\title{
Immune Modulation Effect of Pig Placenta Extracts in a Mouse Model: Putative Use as a Functional Food Supplement
}

\author{
Hyun Jung Park, Han Geuk Suh ${ }^{1}$, Jin Hoi Kim¹, Aera Jang ${ }^{2}$, Hyun Jung Jung ${ }^{3}$, \\ Sung Dae Lee ${ }^{3}$, Woo Tae Ha, Ran Lee, Ji Hyuk Kim², Sang Ho Kim³, \\ Si Heung Sung, Sang Ho Moon, Bokyung Kim ${ }^{4}$, and Hyuk Song* \\ Department of Animal and Food Bioscience, Konkuk University, Chungju 380-701, Korea \\ ${ }^{1}$ Major of Animal Biotechnology, College of Animal Biotechnology, Konkuk University, Seoul 143-701, Korea \\ ${ }^{2}$ National Institute of Animal Science, RDA, Suwon 441-744, Korea \\ ${ }^{3}$ National Institute of Animal Science, RDA, Cheonan 330-801, Korea \\ ${ }^{4}$ Department of Physiology, Konkuk University, Chungju 380-701, Korea
}

\begin{abstract}
This study was performed to establish an effective extraction method of pig placenta extract that could be used for a putative functional food supplement with immunomodulatory effects. In the present study, we used different temperatures (4, $37,60,80$, and $100^{\circ} \mathrm{C}$ ) and different solvents (chloroform, $\mathrm{NaOH}$, and phosphate buffered saline [PBS]) to extract the pig placenta. Among the different placenta extracts yielded by the different extraction methods, placenta extract (PE) in PBS at $80^{\circ} \mathrm{C}$ for $30 \mathrm{~min}$ (referred to as PE-PBS80) showed a significant increase of nitric oxide production of up to $22.97 \mu \mathrm{M} / 10^{5}$ cells at a $1 \mathrm{mg} / \mathrm{mL}$ dose $(p<0.05)$ in J774A.1 cells than other extracts and control tested. Using PE-PBS80, further animal challenges were performed to identify the immune-enhanced effects. As a result, orally administered PE-PBS 80 showed a significant increase in blood $\mathrm{T}$ and $\mathrm{B}$ cell activities and immunoglobulin (IgG and IgM) production. IgG and IgM levels increased to $41.53 \mathrm{mg} / \mathrm{mL}$ at a $20 \mathrm{mg}$ dose on day 7 and to $27.38 \mathrm{mg} / \mathrm{mL}$ at a $10 \mathrm{mg}$ dose on day 14 , respectively $(p<0.05)$. Furthermore, PE-PBS 80 was also able to significantly enhance the immune modulator cytokine levels $(p<0.05)$ compared to the control and vehicle treatments. Among the evaluated cytokines, the tumor necrosis factor- $\alpha$ (TNF- $\alpha$ ) level increased to $28.89 \mathrm{pg} / \mathrm{mL}$ at extract doses of 20 and $50 \mathrm{mg}$, the interleukin- $1 \beta$ (IL-1 $\beta$ ) level increased to $21.52 \mathrm{pg} / \mathrm{mL}$ at extract doses of $10,20,50$ and $75 \mathrm{mg}$ and the interferon (IFN)- $\gamma$ level increased to $18.24 \mathrm{pg} / \mathrm{mL}$ at extract doses of 10, 20, and $50 \mathrm{mg}$. Therefore, this study presents an effective method for extracting pig placenta extracts and also demonstrates that pig placenta extracts had significant immunomodulatory effects not only at the cellular level but also in a mouse model, suggesting that this material could be used as an excellent candidate functional food supplement.
\end{abstract}

Key words: placental extract, immune modulator, immunoglobulin, cytokine, temperature, lymphocyte

\section{Introduction}

The placenta is a temporary organ that is present in females during gestation and supplies oxygen and nutrients to the developing fetus. The placenta is discharged from the mother's body when the fetus is born. The nutritional substances and vitamins therein, known as the placental extract (PE), can be extracted. The placenta is considered a reservoir of cytokines, hormones, bioactive peptides, enzymes, growth factors, vitamins and minerals

*Corresponding author: Hyuk Song, Department of Animal and Food Science, Konkuk University, Chungju 380-701, Korea. Tel: 82-43-840-3522; Fax: 82-43-842-3522; E-mail: lovelyhusband @kku.ac.kr
(Togashi et al., 2002). PE also contains many valuable bioactive compounds that have various bio-capabilities, including inhibition of aging, inflammation, sunburn, gene mutation, anaphylacticity and oxidation (Kim et al., 2003). PE has been used as a biomedicine for wound healing in Korean folk medicine (Hu, 1994a,b), and the immunomodulatory effects of human PE have been demonstrated in multiple studies.

The benefits of topical use of PE on chronic and nonhealing wounds have recently been reported (Tiwary et al., 2006), and the anti-inammatory effect of human PE has been observed in rheumatoid arthritis and carrageenan-induced edema (Banerjee et al., 1992; Rosenthal, 1982). The mechanism of its anti-inammatory action has been shown to be exerted in part by inhibition of platelet 
aggregation (Kumar et al., 2003). PE is widely marketed in Asian countries for its wound healing, immunotropic and anti-inammatory activities (Biswas et al., 2001). In clinical settings, human placental extracts have been approved and used as therapeutic drugs to improve chronic liver dysfunction and menopausal symptoms in several Asian countries (Kong et al., 2008; Wu et al., 2008). Accumulating studies have demonstrated that the human placenta has multiple functions as a source as well as a target of numerous biologically active molecules $(\mathrm{Qu}$ et al., 1993; Uehara et al., 1995; Wolf et al., 1991). Extraction solvent and temperature may play a pivotal role in isolation of certain active principles from placental tissues (Gupta and Chattopadhyay, 2009).

Although placental extract has been shown elsewhere to have many positive potent biological effects, the effect of PE obtained by different extraction conditions has yet to be elucidated. In this study, the optimal extraction protocol for obtaining the placenta extracts that have effective immunomodulatory ability has been established, and the extracted pig placenta extracts were tested and verified to determine their immune-enhancing effects in both in vitro cultured cell systems and a mouse model that measured the cellular activity parameters, immunoglobulin (Ig) production and changes in blood cytokine concentration.

\section{Materials and Methods}

\section{Preparation of placental extracts}

The pig placentas obtained from normal delivery were washed thoroughly with phosphate buffered saline (PBS) and chopped into small pieces $(<1 \mathrm{~cm})$, and the sliced tissues were resuspended in PBS and freeze-dried to eliminate any residual liquid (Georgieva et al., 1995). Freezedried placental tissues then underwent extraction by homogenization using aqueous $\mathrm{PBS}$ and $\mathrm{NaOH}$. To perform the extraction, freeze-dried samples were resuspended with PBS at a concentration of 5:1 (w/v) and homogenized using an X620 universal homogenizer (Ultraturax; Staufen im Breisgau, Germany). The homogenized soluble materials were filtered with the Quantitative Ashless 5A filter papers filter papers (Advantec, Toyo, Japan) for removal of the larger insoluble materials and were the filtered aqueous materials were freeze-dried by lyophilization and stored at $-80^{\circ} \mathrm{C}$ until use. For the aqueous PBS extraction, the freeze-dried placenta samples were ground using an HR2020 blender (Phillips, China) for $30 \mathrm{~s}$, and the grinded materials (powders) then underwent further extractions in which the placental powder was resuspended in PBS at a concentration of 5:1 (w/v) and incubated for the indicated period of time at the indicated temperature: $4^{\circ} \mathrm{C}$ overnight ("PE-PBS4"), $37^{\circ} \mathrm{C}$ for $3 \mathrm{~h}$ ("PE-PBS37"), $60^{\circ} \mathrm{C}$ for $1 \mathrm{~h}$ ("PE-PBS60"), $80^{\circ} \mathrm{C}$ for 30 min ("PE-PBS80") and $100^{\circ} \mathrm{C}$ for $10 \mathrm{~min}$ in PBS ("PEPBS100"). After the extraction, each of the extracts was filtered using the Quantitative Ashless 5A filter papers to remove the larger insoluble materials, and the filtered soluble materials were freeze-dried by lyophilization and stored at $-80^{\circ} \mathrm{C}$ until use. For the $\mathrm{NaOH}$ extract, the ground materials (powders) were incubated with boiled $0.5 \mathrm{M} \mathrm{NaOH}$ for $1 \mathrm{~h}$. After the extraction, the $\mathrm{NaOH}$ extracts ("PE-NaOH") were filtered using the Quantitative Ashless 5A filter papers filter papers to remove the larger insoluble materials, and the filtered soluble materials were freeze-dried by lyophilization and stored at $-80^{\circ} \mathrm{C}$ until use. For the total fatty acid extraction ("PE-TFA"), freeze-dried placental tissues were applied to a 2:1 chloroform-methanol $(\mathrm{v} / \mathrm{v})$ solvent as described previously (Folch et al., 1957). The solution was then treated with a saturated solution of $\mathrm{NaCl}(40 \%$ in volume with respect to the organic phase) in a separation funnel tube.

\section{Nitric oxide production assay}

Nitric oxide (NO), a stable oxidative metabolite, was measured as described previously (Green et al., 1982). Briefly, J774A.1 cells (ATCC, USA) plated in 12-well plates at a density of $1 \times 10^{5}$ cells and treated with $10 \mathrm{U} /$ $\mathrm{mL}$ interferon (IFN)- $\gamma$ (positive control) (R\&D system, USA) $100 \mathrm{ng} / \mathrm{mL}$ lipopolysaccharide (LPS) (Sigma, USA) and $10 \mathrm{U} / \mathrm{mL}$ IFN- $\gamma$ with $0.1,0.5$ and $1.0 \mathrm{mg} / \mathrm{mL}$ extracts were added separately to the reaction mixture and then incubated for $48 \mathrm{~h}$. At the end of the incubation, $100 \mu \mathrm{L}$ of the culture medium was mixed with an equal volume of Griess reagent [1 part of $0.1 \% N$-(1-naphthyl)-ethylenediamine dihydrochloride and one part of $1 \%$ sulfanilamide in 5\% phosphoric acid] and allowed to stand at room temperature for $5 \mathrm{~min}$. The absorbance at $540 \mathrm{~nm}$ was measured using a Tecan Infinite F200 microplate reader (Tecan Austria GmbH, Austria), while the nitrite concentration was determined using a curve calibrated on sodium nitrite standards.

\section{Animals}

Male BALB/c mice (Central lab Inc., Korea) 5 wk of age were housed in a conventional temperature- and humidity-controlled room and provided standard laboratory food and water. 


\section{Group design and experiment}

Six groups of mice (20 mice per group) were used in the study. Group 1 included normal healthy mice that were not treated with a placenta extract or vehicle $(1 \times \mathrm{PBS})$ for 3 wk. Group 2 included animals that were treated with an oral dose of $1 \times \mathrm{PBS}$ as a vehicle for $3 \mathrm{wk}$. Group 3 included animals that were treated with an oral dose of $10 \mathrm{mg}$ PEPBS80 dissolved in water every day for $3 \mathrm{wk}$. Group 4 included animals that were treated with an oral dose of 20 $\mathrm{mg}$ of PE-PBS80 dissolved in water every day for $3 \mathrm{wk}$. Group 5 included animals that were treated with an oral dose of $50 \mathrm{mg}$ of PE-PBS80 dissolved in water every day for $3 \mathrm{wk}$. Group 6 included animals that were treated with an oral dose of $75 \mathrm{mg}$ of PE-PBS80 dissolved in water every day for $3 \mathrm{wk}$. The changes in body weight of each mouse were measured every $7 \mathrm{~d}$ during the placenta extract treatment.

\section{Plasma and lymphocyte preparation}

Five mice from each experimental group were sequentially sacrificed on days $4,7,14$, and 21 of the experimental period and total blood samples were collected via direct heart puncture. Approximately $1 \mathrm{~mL}$ of blood was collected in ethylenediaminetetraacetic acid (EDTA) containing tubes (Becton Dickinson, USA), and then $0.5 \mathrm{~mL}$ of whole blood was mixed with $0.5 \mathrm{~mL}$ of Histopaque1077 (Sigma, USA) and centrifuged at 1,200 g for 20 min. The lymphocyte cells were carefully isolated from the middle of the gradient. To separate the plasma, 0.5 $\mathrm{mL}$ of whole blood was incubated for $1 \mathrm{~h}$ at room temperature and then the samples were centrifuged at 3,500 rpm for $15 \mathrm{~min}$, after which time the supernatant was carefully collected and stored at $-70^{\circ} \mathrm{C}$ until use.

\section{Measurement of mouse lymphocyte activation with treatment of placental extract}

Isolated lymphocytes $\left(5 \times 10^{5}\right.$ cells $)$ from each treated group by week were plated on 96-well plates and incubated for $1 \mathrm{~h}$ at $37^{\circ} \mathrm{C}$. LPS $(2.5 \mu \mathrm{g} / \mathrm{mL})$ was added to cultured cells to identify the B lymphocyte activities and 2.5 $\mathrm{ug} / \mathrm{mL}$ concavalin A (ConA) (Sigma, USA) was added to assess $\mathrm{T}$ lymphocyte activities. Cells were then incubated for a further $48 \mathrm{~h}$. Cell viability and proliferation were analyzed using an MTT assay kit (TACS, USA) according to the manufacturer's instructions, and the cell proliferation rate was determined based on the absorbance at $550 \mathrm{~nm}$ using a SUNRISE-BASIC TECAN microplate reader (Tecan Austria, Austria).
Immunoglobulin and cytokine levels assessment by enzyme-linked immunosorbent assay

The IgG and IgM concentrations in the total blood samples were measured using a mouse IgG and IgM enzymelinked immunosorbent assay (ELISA) Quantitation Kit (Bethyl Laboratory Inc., USA). Anti-mouse IgG and IgM ( $1 \mu \mathrm{g}$ each; Bethyl Laboratory Inc., USA) antibodies were diluted using $100 \mu \mathrm{L}$ of coating buffer and incubated for $1 \mathrm{~h}$ on 96-well plates. The non-binding excessive antibody was then aspirated and the plates were washed three times using washing solution. Blocking solution $(200 \mu \mathrm{L})$ was then added and the samples were incubated for 30 min and $100 \mu \mathrm{L}$ of reaction mixture was added to the samples, which were then incubated for an additional $1 \mathrm{~h}$. The samples were then washed five times with washing solution (provided by the manufacturer). Horseradish peroxidase (HRP)-conjugated secondary antibody (Bethyl Laboratory Inc., USA) was added and the samples were incubated for $1 \mathrm{~h}$ at room temperature. The HRP solution was then removed and the samples were washed five times with washing solution. TMB solution $(100 \mu \mathrm{L}$ per well; Bethyl Laboratory Inc., USA) was added and the samples were incubated for $20 \mathrm{~min}$ at room temperature. Finally, $100 \mu \mathrm{L}$ of $\mathrm{H}_{2} \mathrm{SO}_{4}$ was added and the concentration of each Ig was determined based on the absorbance at $450 \mathrm{~nm}$ using a SUNRISE-BASIC TECAN microplate reader.

Interleukin (IL)-10, IL-6, IL-1 $\beta$, tumor necrosis factor alpha (TNF- $\alpha$ ) and IFN- $\gamma$ levels were measured in undiluted plasma using a commercially available mice cytokine detection ELISA kit (R\&D Systems, USA) according to the manufacturer's instructions. Briefly, $50 \mu \mathrm{L}$ of the assay diluent RD1-63 (R\&D Systems) was added to each anti-cytokine antibody-coated microplates, and then 7.8$2,000 \mathrm{pg} / \mathrm{mL}$ of each cytokine protein was added to measure the standard binding to the coated antibody as a quantitative control, while plasma samples were added to the microplates to measure the concentration of plasma cytokine concentration. The standard proteins and plasma samples were then incubated for $2 \mathrm{~h}$ at room temperature. After incubation, the mixtures were aspirated and the microplate wells were washed with washing solution provided by the manufacturer. Polyclonal antibody of each cytokine $(100 \mu \mathrm{L}$ each of TNF- $\alpha$, IL- $1 \beta$, IL-6, IFN- $\gamma$ and IL-10) conjugated with biotin were added to the microplate wells. All of the mixtures were incubated for $2 \mathrm{~h}$ at room temperature and the excessive non-binding materials were aspirated and washed. Streptavidin substrate solution (100 $\mu \mathrm{L}$; R\&D Systems) was added and incu- 
bated for $30 \mathrm{~min}$ at room temperature. Finally, $100 \mu \mathrm{L}$ of stop solution was added and the cytokine concentrations were determined based on absorbance at $450 \mathrm{~nm}$ using a SUNRISE-BASIC TECAN microplate reader (Tecan, Austria).

\section{Statistical analysis}

The SPSS statistical package ver. 15.0 for Windows (IBM Corp., USA) was utilized for the data analysis. All data were expressed as means. The control and sample treatment values were compared by paired $t$-test. The null hypothesis was rejected when the probability was $<0.05$.

\section{Results and Discussion}

\section{Ability of PE to induce NO production}

It has been demonstrated that NO plays an important role in wound healing as a mediator of tissue repair. NO is produced at the time of wound healing during inflammation through the action of infiltrating macrophages and dermal fibroblasts (Wang et al., 1996). In this study, as a first step, the PE capabilities (extracted at different temperatures with different solvents as discussed in Materials and Methods) was tested along with $10 \mathrm{U} / \mathrm{mL}$ of IFN- $\gamma$ for the selection of an effective extraction method using an NO production assay in J774A.1 cells. Based on preliminary screening (Fig. 1A), both PE-PBS100 and PEPBS80 were selected to analyze their NO production abilities in a dose-dependent manner after $48 \mathrm{~h}$ because both extracts showed significant NO production when treated with IFN (Fig. 1A). Fig. 1B clearly indicates that both PE-PBS80 and PE-PBS100 showed significantly increased NO production in a dose-dependant manner when combined with IFN. Indeed, PE-PBS80 showed high NO production up to $22.97 \mu \mathrm{M} / 10^{5}$ cells in $1 \mathrm{mg} / \mathrm{mL}$-treated cells; however, PE-homogenized, PE-PBS60 and PE-NaOH extracts, which were used for the negative controls, did not show increased NO production. These data suggest that both PE-PBS80 and PE-PBS100 may contain effective materials to activate the NO-producing cells.

Generally, if an external stimulus is capable of inducing NO production in macrophages in vitro, it induces NO synthase (NOS) expression in macrophages by some pathway. Basically, IFN- $\gamma$ plays a key role to induce NO production in mice macrophages by the inducible effect of activated interferon releasing factor 1 (IRF1) on the NOS pathway (Kamijo et al., 1994). In this study, considerable accumulation of $\mathrm{NO}$ in J774A.1 cells with co-treatment of either IFN- $\gamma$ or PE-PBS80 and PE-PBS100 was
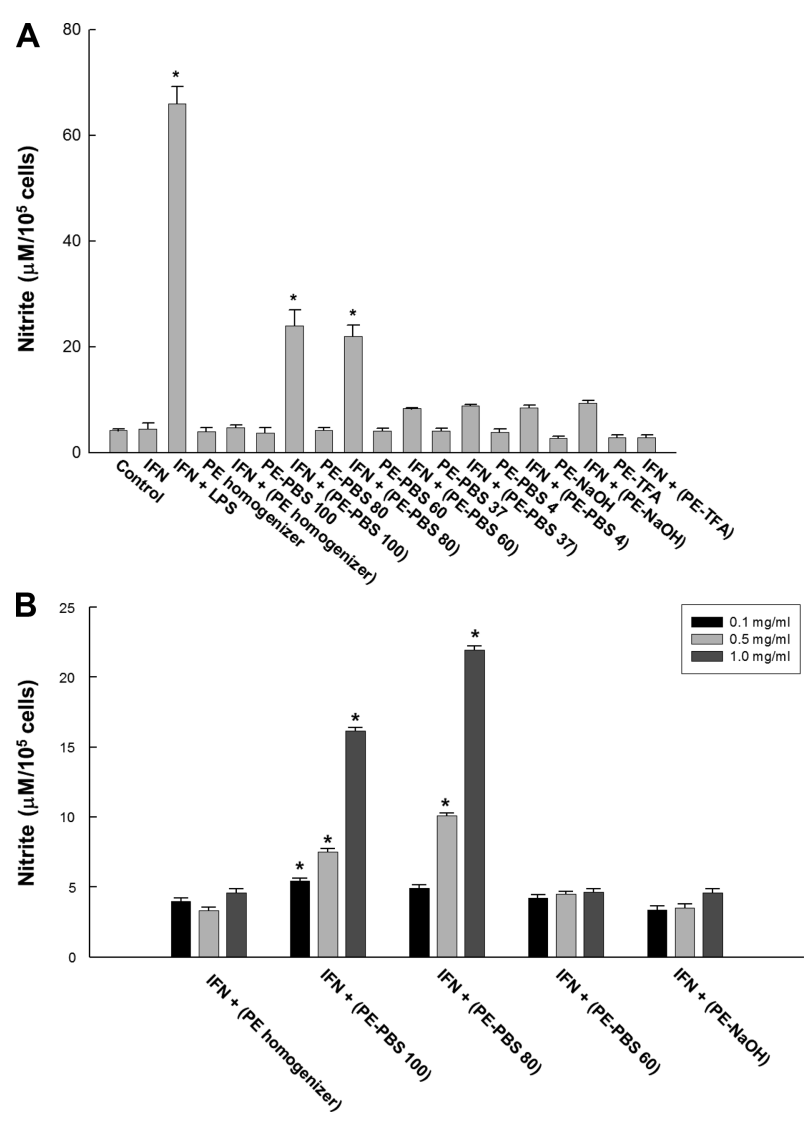

Fig. 1. Inducible effect of placental extracts (PE) on nitric oxide (NO) production in J774A.1 cells. (A) J774A.1 cells $\left(1 \times 10^{5}\right)$ were treated with PE (extracted using different temperatures and solvents) at $0.5 \mathrm{mg} / \mathrm{mL}$. Interferon (IFN)- $\gamma(10 \mathrm{U} / \mathrm{mL})$ served as a positive control and also supplemented the PE. NO levels were measured after 48 $\mathrm{h}$ of incubation. (B) The dose dependence of PE $(0.1,0.5$, and $1 \mathrm{mg} / \mathrm{mL})$ along with IFN- $\gamma(10 \mathrm{U} / \mathrm{mL})$ on NO production in J774A. 1 cells was measured after $48 \mathrm{~h}$ of incubation as described above. Values are presented as mean $\pm \mathrm{SD}(p<0.05)$.

observed, but treatment of IFN- $\gamma$, PE-PBS80, or PEPBS100 alone did not alter NO production in J774A.1 macrophage cells. This finding could be due to the activation of transcriptional factors (such as IRF1) that are responsible for NO synthesis in J774A.1 cells by the synergistic effect of both IFN- $\gamma$ and PE-PBS80. Similarly, IFN- $\gamma$ and LPS exhibit a synergistic effect on the induction of high-output NO production in murine vascular endothelial cells (Huang et al., 2003; Morikawa et al., 2000; Walter et al., 1994). Increased NO production from macrophages leads to three possibilities: increased NOS expression, increased substrate availability, or both. By supporting these statements, PE-PBS80 could possibly constitute a considerable amount of substrate that can better induce NO production in J774A.1 cells than the other extracts. 


\section{Immune cell ( $B$ and $T$ cell) activation by PE-PBS80}

Based on the placenta extract-induced ability of J774A.1 cells to produce NO, PE-PBS80 was selected for the further experiments of the mouse challenge test to determine the immune enhancement and to define this extract as a possible functional food supplement. Mice were treated with different concentrations of PE-PBS80 (10, 20, 50, and $75 \mathrm{mg} / \mathrm{mouse}$ ) as described in Materials and Methods, and the lymphocytes were isolated at treatment days 4, 7, 14 and 21. LPS $(2.5 \mu \mathrm{g} / \mathrm{mL})$ and ConA $(2.5 \mu \mathrm{g} / \mathrm{mL})$ were added to the isolated lymphocytes to activate the $\mathrm{B}$ and $\mathrm{T}$ cells, respectively. The effects of PE-PBS80 on T and $B$ cell activity were higher than those of control and vehicle treatment regardless of PE-PBS80 concentration (Fig. 2), and no statistical significances were seen in the PE-PBS80 treatment group between days 4 and 14 (Fig. 2). Although concentrations $<10 \mathrm{mg}$ were not tested in this experiment, even $10 \mathrm{mg}$ PE-PBS80 treatment clearly showed an almost maximum increase in lymphocytes activity against the antigens LPS and ConA. Therefore, these data suggested that PE-PBS80 has an immunomodulatory effects on lymphocytes.

Generally the fetal placenta of pigs produces substances that stimulate and induce the mitogen-induced lymphocyte proliferation and subsequently activate $\mathrm{B}$ and $\mathrm{T}$ cells. As a consequence, placenta used in this study may also contain the effective mitogenic factors. Therefore B cell activation was increased to 1.07 with $10 \mathrm{mg}$ treatment at day 7 , while $\mathrm{T}$ cell activation was increased to 1.14 with $75 \mathrm{mg}$ treatment at day 14 of the experimental period in mice, respectively (Fig. 2). However, cellular activity grad- ually decreased in subsequent intervals. This finding could be due to a declined retention level of the active principle of PE-PBS80 in mouse plasma. These kinds of effects do not appear to be species non-specific, a finding that is in agreement with similar studies on other species (Due et al., 1985; Fillion et al., 1991; Gupta et al., 1984). Although the molecular identity of the substances present in PE-PBS80 remains unclear, it can be speculated that the active constituents of the extract could considerably activate the surface receptors of $\mathrm{B}$ and $\mathrm{T}$ cells by sending the signals or by means of chemoattractants; eventually, these cells are ready to exhibit a humoral response against invading infection-causing organisms. In addition, these data also suggest that short-term ( 7 to $14 \mathrm{~d}$ ) administration of PE-PBS80 is more effective on lymphocyte activation than long-term $(>14 \mathrm{~d})$ exposure.

However, the possibility that PE-PBS80 could be acting as an antigen cannot be ruled out; therefore, PE-PBS80treated mice were immunized or adapted by PE-PBS80 administration. As a result, less activity is seen in collected B cells after day 14 and in T cells after day 21 than in cells isolated from earlier treatment. Similar observations were reported in which mice that were orally administered a plant extract showed an adaptive immune response. Increased lymphocyte activation and immunoglobulin production were seen until the animals adapted to the antigen, but these levels occasionally decreased or plateaued after adaptation (Liang et al., 2005).

\section{Effect of PE-PBS80 on mouse Ig levels}

To determine the ability of PE-PBS 80 to enhance blood
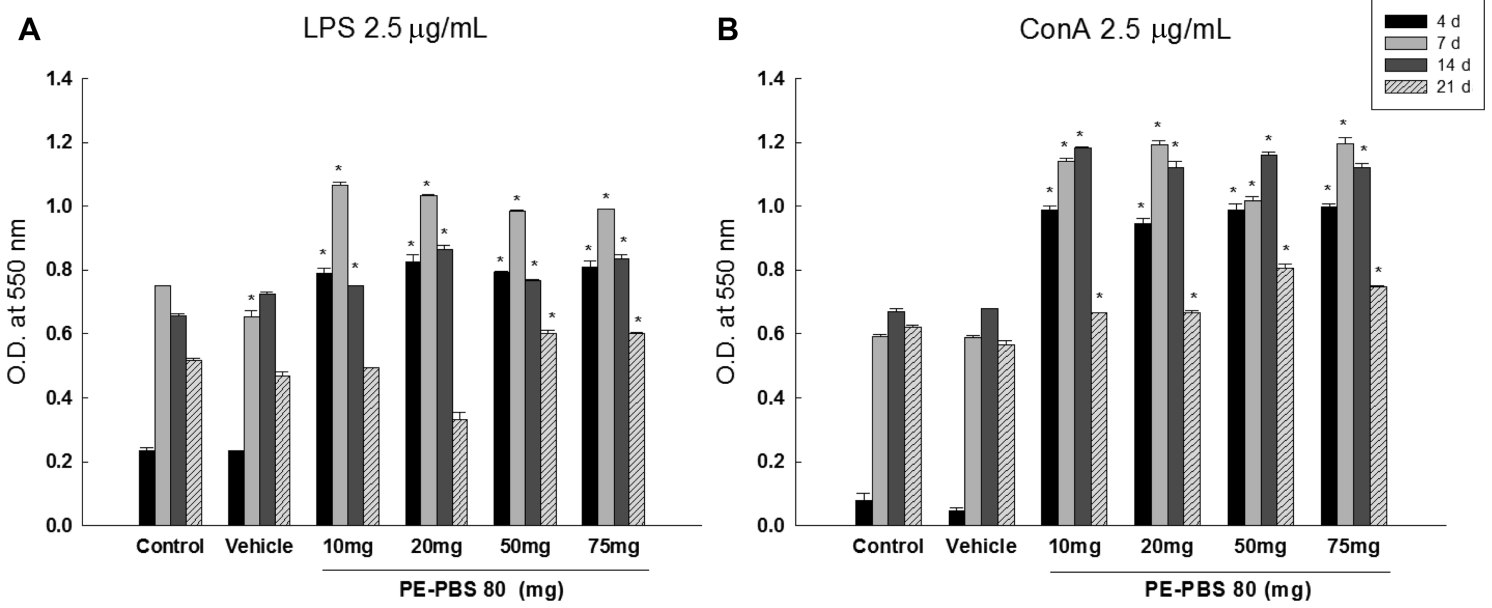

Fig. 2. B and T cell activation by PE-PBS80 (extracted using phosphate buffered saline at $80^{\circ} \mathrm{C}$ ). (A) Lymphocytes were isolated from PE-PBS80 (at 10, 20, 50, and $75 \mathrm{mg}$ )-treated mice on 4, 7, 14, and $21 \mathrm{~d}$. Isolated lymphocytes $\left(5 \times 10^{5}\right.$ cells) were treated with $2.5 \mu \mathrm{g} / \mathrm{mL}$ of lipopolysaccharide (LPS) for B cell activation and their viability was determined by MTT assay after $48 \mathrm{~h}$ of incubation. (B) Isolated lymphocytes $\left(5 \times 10^{5}\right.$ cells) were treated with $2.5 \mu \mathrm{g} / \mathrm{mL}$ concavalin A (ConA) for T cell activation and their viability was determined using an MTT assay after $48 \mathrm{~h}$ of incubation. Values are presented as means $\pm \mathrm{SD}(p<0.05)$. 
Ig levels in mice, the $\operatorname{IgG}$ and $\operatorname{IgM}$ concentrations in the blood were analyzed. A significant increase in blood $\operatorname{IgG}$ concentration was observed at days 4,7 , and 14 on 10 and $20 \mathrm{mg}$ of PE-PBS80 treatment and at day 4 on $50 \mathrm{mg}$ of PE-PBS 80 treatment compared to control and vehicletreated mice. Significant increases in blood IgG concentrations were also seen at days 4 and 7 on $75 \mathrm{mg}$ of PEPBS80 treatment compared to control and vehicle-treated mice (Fig. 3). For blood IgM concentration, treatment with 10 and $20 \mathrm{mg}$ PE-PBS80 showed significant increases at days 14 and 21, while treatment with 50 and $75 \mathrm{mg}$ showed significant increases at days 7, 14 and 21 (Fig. 3). The maximum increases of both $\mathrm{IgG}$ and IgM were 41.53 $\mathrm{mg} / \mathrm{mL}$ at $20 \mathrm{mg}$ treatment on day 7 and $27.38 \mathrm{mg} / \mathrm{mL}$ at $10 \mathrm{mg}$ treatment on day 14 , respectively $(p<0.05)$ (Fig. $3)$.

Interestingly, treatment with lower concentrations (10 and $20 \mathrm{mg}$ ) of PE-PBS80 showed maximum increases of blood IgG concentration on days 4 and 7 and gradually decreased on days 14 and 21 (Fig. 3). In addition, treatment with 50 and $75 \mathrm{mg}$ showed overall lower IgG concentrations than treatment with 10 and $20 \mathrm{mg}$, although only days 4 and 7 showed significant increases of IgG concentrations compared to controls and at day 14 , these differences lost significance. However, blood IgM concentrations showed opposite patterns to those of blood IgG concentrations in that treatment with 10 and $20 \mathrm{mg}$ of PE-PBS80 showed increased IgM concentrations at days 14 and 21, whereas treatment with 50 and $75 \mathrm{mg}$ showed significantly increased blood IgM concentrations

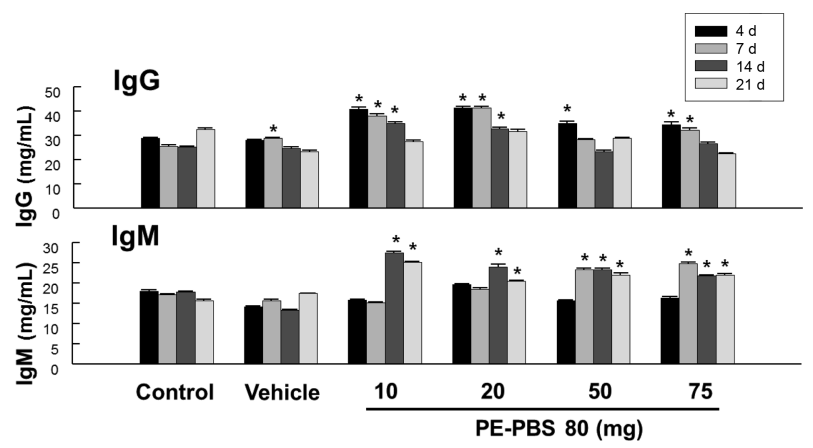

Fig. 3. Influence of PE-PBS80 on mice immunoglobulin (IgG and IgM) production. Blood samples were collected from $\mathrm{PE}$ (phosphate buffered saline at $-80^{\circ} \mathrm{C}$; concentrations of $10,20,50$, and $75 \mathrm{mg}$ ) treated mice on $4,7,14$ and $21 \mathrm{~d}$. Samples incubated with anti-mouse IgG and IgM antibodies. Horseradish peroxidase (HRP)-conjugated secondary antibody was used to detect the absorbance of each Ig using SUNRISE-BASIC TECAN microplate reader at $450 \mathrm{~nm}$. Values are presented as means \pm $\mathrm{SD}(p<0.05)$. at day 7 (Fig. 3).

This finding is possibly a sign of the induction of a switch to IgG and IgM of the Ig class secreted in activated $\mathrm{B}$ cells, or a selective activation of their precursors. Bobe et al. (1984) demonstrated that two soluble factors from PE can deviate and enhance the specific antibody response to alloantigens and sheep red blood cells. Although they have shown that these factors are dependent on the simultaneous presence of antigen to exert their action in vivo (Bobe et al., 1986), this does not necessarily imply that there cannot be a general action in vitro. Consequently, it is possible that one (or both) of the factors described by Bobe et al. $(1984,1986)$ may also cause a switch to IgG and IgM production following PEPBS80 treatment.

In addition, the possibility of adaptive immune response of PE-PBS80 described in above "Immune cells (B and T cells) activation by PE-PBS80" section cannot be ruled out because $\operatorname{IgG}$ concentrations in PE-PBS80-treated mice increased until day 7 and decreased thereafter. However, the concentration of IgM is directly opposite that of IgG, suggesting the possibility that adaptive immune responses should be very rare.

\section{Effect of PE-PBS80 on cytokine levels in mice}

Under physiological and pathological conditions, white blood cells participate in immunomodulating effects by directly releasing cytokines. Since PE have been extensively reported for their immunomodulatory effects (e.g., wound healing) (Dayer et al,. 1985) involving stimulation of immune cells to secrete cytokines, it was logical to investigate the capability of PE-PBS80 on inducing cytokine secretion in mice.

To identify the response of PE-PBS 80 as an immunomodulator, the blood concentrations of TNF- $\alpha$, IL- $1 \beta$, IL6 , IFN- $\gamma$ and IL-10 were analyzed in mice blood plasma at different experimental intervals $(4,7,14$, and $21 \mathrm{~d})$ with administration of 10, 20, 50 and $75 \mathrm{mg}$. PE-PBS80 exert a significant positive effect $(p<0.05)$ by increasing cytokine level maximums at different time intervals at different concentration. PE-PBS80 was also able to significantly enhance the cytokine levels $(p<0.05)$ compared to the control and vehicle treatment groups. Among the evaluated cytokines, TNF- $\alpha$ increased to $28.89 \mathrm{pg} / \mathrm{mL}$ with administration of 20 and $50 \mathrm{mg}$ of extract, IL-1 $\beta$ increased to $21.52 \mathrm{pg} / \mathrm{mL}$ with administration of 10,20 , 50 , and $75 \mathrm{mg}$ of extract and IL-6 increased to $18.32 \mathrm{pg} /$ $\mathrm{mL}$ with administration of $75 \mathrm{mg}$ of extract (Fig. 4A). In addition, IFN- $\gamma$ increased to $18.24 \mathrm{pg} / \mathrm{mL}$ with adminis- 
tration of 10, 20, and $50 \mathrm{mg}$ of extract; however, the IL10 concentration did not increase (Fig. 4B).

IL- $1 \beta$ is a lymphocyte mitogen that has been known as a lymphocyte-activating factor that activates lymphocytes and is involved in cell proliferation, differentiation and apoptosis (Skotnicka and Hassmann, 2008), while TNF- $\alpha$ is involved in systemic inflammation, immune cell regulation and promotion of IL-1 and IFN- $\gamma$ synthesis (Chatzidakis and Mamalaki, 2010). IFN- $\gamma$, a representative cytokine of immune cell activation, increased when the cells were infected by the antigens; therefore, it is used as

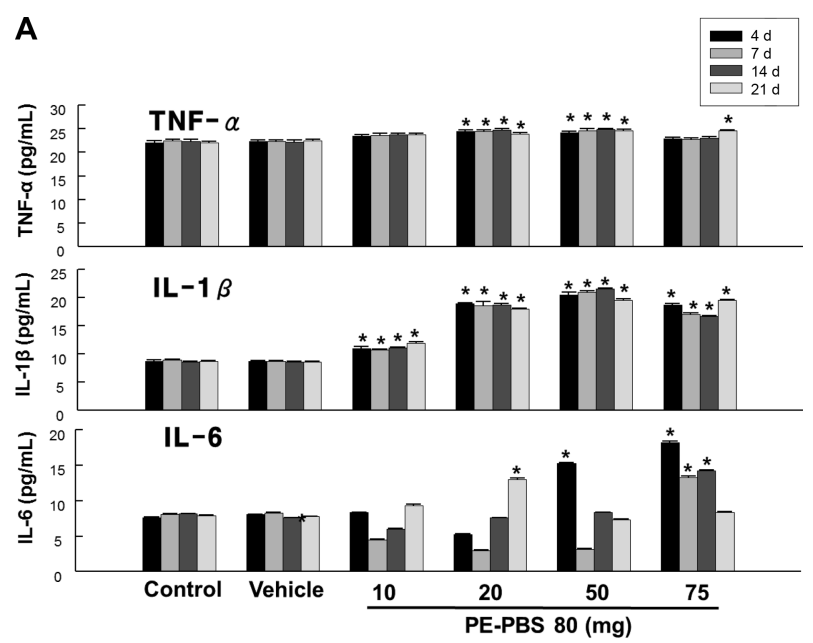

B

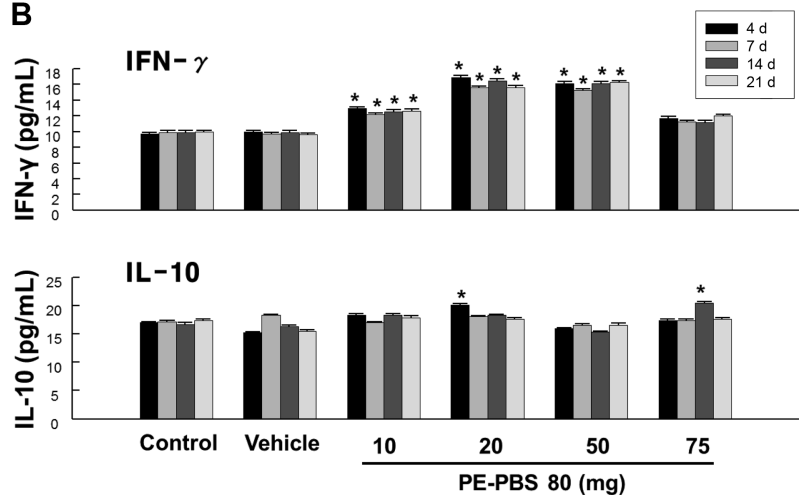

Fig. 4. Cytokine (tumor necrosis factor- $\alpha$ [TNF- $\alpha]$, interleukin $[\mathrm{IL}]-1 \beta$, IL-6, interferon [IFN]- $\gamma$ and IL-10) levels in PE-PBS80-treated mice. (A) Blood samples were collected from PE-PBS80 (at 10, 20, 50, and $75 \mathrm{mg}$ )-treated mice on days $4,7,14$, and 21 , and the plasma was separated. Plasma samples were added to anti-cytokine (TNF$\alpha$, IL-1 $\beta$ and IL-6) antibody-coated microplates and incubated for $2 \mathrm{~h}$. A biotin-conjugated polyclonal antibody of each cytokine (TNF- $\alpha$, IL-1 $\beta$, and IL-6) was added and incubated for $2 \mathrm{~h}$ at room temperature and the cytokines were quantified by measuring the absorbance at $450 \mathrm{~nm}$ after adding streptavidin substrate. (B) Plasma samples were added to anti-cytokine (IFN- $\gamma$ and IL-10) antibodycoated microplates and incubated for $2 \mathrm{~h}$ and measured as described above. Values are presented as means $\pm \mathrm{SD}$ $(p<0.05)$. an anti-viral drug. IL-6 has both pro- and anti-inflammation activities and stimulates the immune response. In addition, IL- 6 synthesis is generally activated by IL-1 but is suppressed by IL-10 (Benedict et al., 2009). IL-6 is also involved in $\mathrm{B}$ and regulatory $\mathrm{T}$ lymphocyte growth (Benedict et al., 2009). IL-10 is known as a cytokine synthesis inhibitory factor (CSIF) that inhibits IL-6, IFN- $\gamma$ and TNF- $\alpha$ synthesis (Skotnicka and Hassmann, 2008).

Interestingly, the concentrations of TNF- $\alpha$, IL- $1 \beta$ and IFN- $\gamma$ were increased in response to PE-PBS80, but blood IL-10 concentrations did not change or even decrease at $50 \mathrm{mg}$ administration compared to control and vehicle treatment (Fig. 4). This finding is remarkable because TNF- $\alpha$, IL- $1 \beta$, and IFN- $\gamma$ are known to enhance immune modulation; however, IL-10 inhibits the synthesis of these cytokines (Benedict et al., 2009). Although the mechanism between IL-1/IL-10 synthesis and PE-PBS80 treatment in mice is not yet clear, PE-PBS80 obviously increased IL$1 \beta$ synthesis; therefore, IL-6 concentrations were increased at a high dose of PE-PBS80 (75 mg) followed by high IL$1 \beta$ serum concentrations. On the other hand, it is possible that physiological induction time and the required amount of active PE-PBS80 principles for the cells to secrete each cytokine could differ.

\section{Effect of PE-PBS80 on mouse body weight}

The body weights of the mice were measured after PEPBS80 treatment with $10,20,50$, and $75 \mathrm{mg} / \mathrm{mL}$ to ensure biosafety and gain recommendation as a food supplement. Fig. 5 showed that that the treated mouse body weights were not increased or decreased compared to the control and vehicle groups. This observation indicates

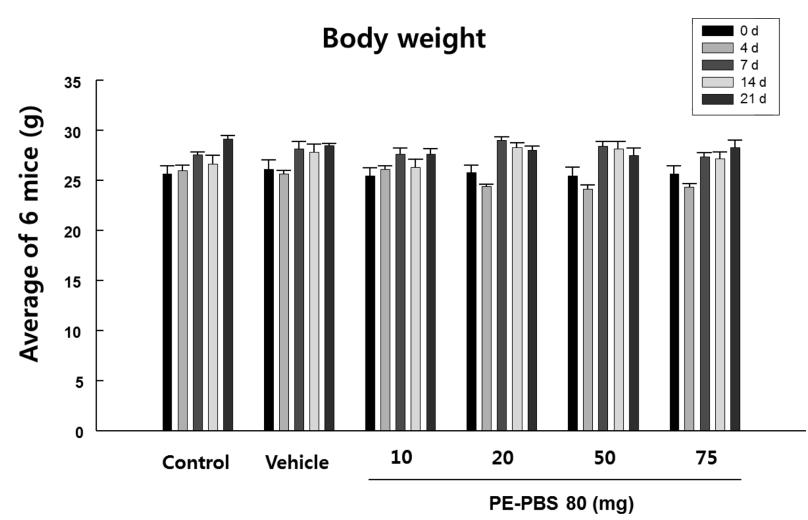

Fig. 5. Effect of placental extracts (PE) (extracted using phosphate buffered saline at $80^{\circ} \mathrm{C}$ ) on mouse body weight. Mice were treated with PE-PBS80 (at concentrations of $10,20,50$, and $75 \mathrm{mg}$ ) and body weights were measured on days $4,7,14$, and 21 . Values are presented as means $\pm \mathrm{SD}(p<0.05)$. 
that PE-PBS80 could not only be a promising immunomodulator but also possibly have no side effects. PEPBS80-treated mice showed a slight increase in body weight without the use of protein- and fat-rich foods, which eventually reduces the risk of obesity and other disorders. This phenomenon could be due to the action of the active PE-PBS80 principles on specific metabolic pathways, which maintains body weight per physiological requirements.

In this study, among the various extract candidates using different extraction methods including different temperature conditions and solvents, use of PE-PBS80, a pig placenta extract using PBS, at $80^{\circ} \mathrm{C}$ was an optimum extract to activate NO production of macrophage cells. Use of this PE-PBS80 in an animal challenge study revealed that this material increased the activity of both $\mathrm{B}$ and $\mathrm{T}$ cells until 7-14 $\mathrm{d}$ of feeding by cell viability measurement after exposure to LPS and ConA. In addition, IgG and IgM production in serum was significantly increased, and levels of cytokines including TNF- $\alpha$, IL-1 $\beta$, IL- 6 , and IFN- $\gamma$ involved in immune modulation were distinctly increased. Basically, the large number of chemokines and other protein-rich chemoattractants should be inactivated by hightemperature extraction. In contrast, the PE-PBS80 preparation in this study involved heat extraction $\left(80^{\circ} \mathrm{C} ; 30\right.$ $\mathrm{min}$ ) and few preparation with terminal sterilization by autoclaving; therefore, the active constituents of PEPBS 80 could be heat stable up to $80^{\circ} \mathrm{C}$. Results of both the in vitro cell activation and the animal challenge study strongly support the idea that the active factors of pig placenta for immunomodulation could be extracted at $80^{\circ} \mathrm{C}$. According to this study, the migration promoting key factor(s) extracted from placenta also heat stable up to $95^{\circ} \mathrm{C}$ (Gupta and Chattopadhyay, 2009).

Although the mechanism involved in this ability of placenta extract is not known, it is obvious that the placenta contains many known and unknown immunomodulation factors for animals and humans. It also enhances the viability of newborn animals, which have immature immune systems, if used for feed supplement for young animals. Further purified and processed factors can be used for therapeutic purposes in both humans and animals. To date, the pig placenta has been recognized as a by-product of delivery and immediately abandoned; however, pig placenta extracts are useful functional food supplements for both humans and animals.

In conclusion, our current studies provided experimental evidence of an effective extraction and preparation protocol for pig placenta extracts, indicating the therapeu- tic potential of pig placenta extracts as immune enhancers and eventual human food supplements. Before reaching a concrete conclusion, the active constituents of pig placental extracts and their immunomodulating mechanisms should be revealed.

\section{Acknowledgements}

This work was carried out with the support of the Cooperative Research Program for Agriculture Science \& Technology Development (Project No. PJ007605) Rural Development Administration, Republic of Korea, and was supported in part by the Technology Development Program for Agriculture and Forestry, Ministry of Agriculture and Forestry.

\section{References}

1. Banerjee, K. K., Bishayee, A., and Chatterjee, M. (1992) Anti-inammatory effect of human placental extract: a biochemical mechanistic approach. Rivista. Europea. per le Scienze Medichee. Farmacologiche. 14, 361-366.

2. Benedict, C., Scheller, J., Rose-John, S., Born, J., and Marshall, L. (2009) Enhancing influence of intranasal interleukin-6 on slow-wave activity and memory consolidation during sleep. FASEB J. 23, 3629-36.

3. Biswas, T. K., Auddy, B., Bhattacharya, N. P., Bhattacharya, S., and Mukherjee, B. (2001) Wound healing activity of human placental extracts in rats. Act. Pharmacol. Sin. 22, 1113-1116.

4. Bobe, P., Doric, M., Kinsky, R. G., and Voisin, G. A. (1984) Modulation of mouse anti-SRBC antibody response by placental extracts. Cell. Immunol. 89, 355-364.

5. Bobe, P., Kanellopoulos-Langevin, C., Bleux, C., and Voisin, G.A. (1986) Modulation of mouse anti-SRBC antibody responses by placental extracts. 11. Antigen specificity and regulatory role of $\mathrm{B}$ and $\mathrm{T}$ cell populations affected by two distinct placental fractions. J. Immunol. 136, 574-581.

6. Chatzidakis, I., and Mamalaki, C. (2010) T cells as sources and targets of TNF: implications for immunity and autoimmunity. Curr. Dir. Autoimmun. 11, 105-118.

7. Dayer, J., M., Beutler, B., and Cerami, A. J. (1985) Cachetin/ tumor necrosis factor stimulates collagenase and prostaglandin E2 production by human synovial cells and dermal fibroblast. Exp. Med. 62, 2163-2168.

8. Due, H. T., Masse, A., Bode, P., Kinsky, R. G., and Voisin, G. A. (1985) Deviation of humoral and cellular alloimmune reactions by placental extracts. J. Reprod. Immunol. 7, 2739.

9. Fillion, C., Chaouat, G., Reinaud, P., Charpigny, J. C., and Martal J. (1991) Immmoregulatory effects of ovine trophoblast in protein (oTP): all 5 isofoirns suppress PHA-induced lymphocyte proliferation. J. Reprod. Immunol. 19, 237-249. 
10. Georgieva, R., Stefanov, D., Fichorova, R., Dimitrova, E. (1995) Effects of the whole extract and the chromatographic fractions of the pig placenta on lymphocyte proliferation and humoral immune response. Theriogenology 44, 539-551.

11. Green, L. C., Wagner, D. A., Glogowski, J., Skipper, P. L., Wishnok, J. S., Tannenbaum, S. R. (1982) Analysis of nitrate, nitrite, and $\left[{ }^{15} \mathrm{~N}\right]$ nitrate in biological fluids. Anal. Biochem. 126, 131-138.

12. Gupta, G. S., Kinsky, R. G., Due, H. T., and Voisin, G. A. (1984) Effects of placental extracts on the immune response to histocompatibility antigens: class deviation of alloantibody response and allograft enhancement. Am. J. Reprod. Immunol. 6, 117- 123.

13. Gupta, R. and Chattopadhyay, D. (2009) Glutamate is the chemotaxis-inducing factor in placental extracts. Amino Acids 37, 359-366.

14. Huang, H., McIntosh, J., and Hoyt, D. G. (2003) An efficient, nonenzymatic method for isolation and culture of murine aortic endothelial cells and their response to inflammatory stimuli. In Vitro Cell Dev. Biol. Anim. 39, 43-50.

15. Kamijo, R., Harada, H., Matsuyama, T., Bosland, M., Gerecitano, J., Shapiro, D., Le, J., Koh, S. I., Kimura, T., and Green S. J. (1994) Requirement for transcription factor IRF1 in NO synthase induction in macrophages. Science 263, $1612-1615$

16. Kim, J. H., Lee, J. W., Kim, Y. I., and Lee M. H. (2003) The effect of placental extract on the expression of tyrosinase, TRP-1 and TRP-2 in SK30 melanoma cells. J. Kor. Derma. Assoc. 41, 1612-1618.

17. Kong, M. H., Lee, E. J., and Lee, S. Y. (2008) Effect of human placental extract on menopausal symptoms, fatigue, and risk factors for cardiovascular disease in middle-aged Korean women. Menopause 15, 296-303.

18. Kumar, S., Kanti, B., Liaquat, A., and Biswapati, M. (2003) Anti-inammatory and antiplatelet aggregation activity of human placental extract. Act. Pharmacol. Sini. 24, 187-192.

19. Liang, W., Huang, Y., Yang, X., Zhou, Z., Pan, A., Qian, B., Huang, C., Chen, J., and Zhang, D. (2006) Oral immunization of mice with plant-derived fimbrial adhesion FaeG induces systemic and mucosal K88ad enterotoxigenic Escherichia coli-specific immune response. FEMS Immunol. Med. Microbiol. 46, 393-399.

20. Morikawa, A., Koide, N., Kato, Y., Sugiyama, T., Chakra- vortty, D., Yoshida, T., and Yokochi, T. (2000) Augmentation of nitric oxide production by gamma interferon in a mouse vascular endothelial cell line and its modulation by tumor necrosis factor alpha and lipopolysaccharide. Infect. Immun. 68, 6209-6214.

21. Qu, J. and Thomas, K. (1993) Regulation of inhibin secretion in human placental cell culture by epidermal growth factor, transforming growth factors, and activin. J. Clin. Endocrinol. Metab. 77, 925-931.

22. Rosenthal, M. (1982) The application of an extract of human placenta in the treatment of rheumatic affections. Int. J. Tiss. Reac. 4, 147- 151.

23. Skotnicka, B. and Hassman, E. (2008) Proinflammatory and immunoregulatory cytokines in the middle ear effusions. Int. J. Pediatr. Otorhinolaryngol. 72, 13-17.

24. Tiwary, S., Shukla, D., Tripathi, A., Agrawal, S., Singh, M., and Shukla, V. (2006) Effect of placental-extract gel and cream on non-healing wounds. J. Wound Care 15, 325-328.

25. Togashi, S., Takahashi, N., Iwama, M., Watanabe, S., Tamagawa, K., and Tetsuya, F. (2002) Antioxidative collagenderived peptides in human-placenta extract. Placenta 23, 497-502.

26. Uehara, Y., Minowa, O., and Mori, C. (1995) Placental defect and embryonic lethality in mice lacking hepatocyte growth factor/scatter factor. Nature 373, 702 -705.

27. Walter, R., Schaffner, A., and Schoedon, G. (1994) Differential regulation of constitutive and inducible nitric oxide production by inflammatory stimuli in murine endothelial cells. Biochem. Biophys. Res. Comm. 202, 450-455.

28. Wang, R., Ghahary, A., Shen, Y. J., Scott, P. G., and Tredget, E. E. (1996) Human dermal fibroblasts produce nitric oxide and express both constitutive and inducible nitric oxide synthase isoforms. J. Invest. Dermatol. 106, 419-427.

29. Wolf, H. K., Zarnegar, R., and Oliver, L. (1991) Hepatocyte growth factor in human placenta and trophoblastic disease. Am. J. Pathol. 138, 1035-1043.

30. Wu, J., Yang, T., and Wang, C. (2008) Laennec protects murine from concanavalin A induced liver injury through inhibition of inammatory reactions and hepatocyte apoptosis. Biol. Pharm. Bull. 31, 2040-2044.

(Received 2011.6.6/Revised 1st 2011.9.21, 2nd 2011.9.24/ Accepted 2011.9.27) 